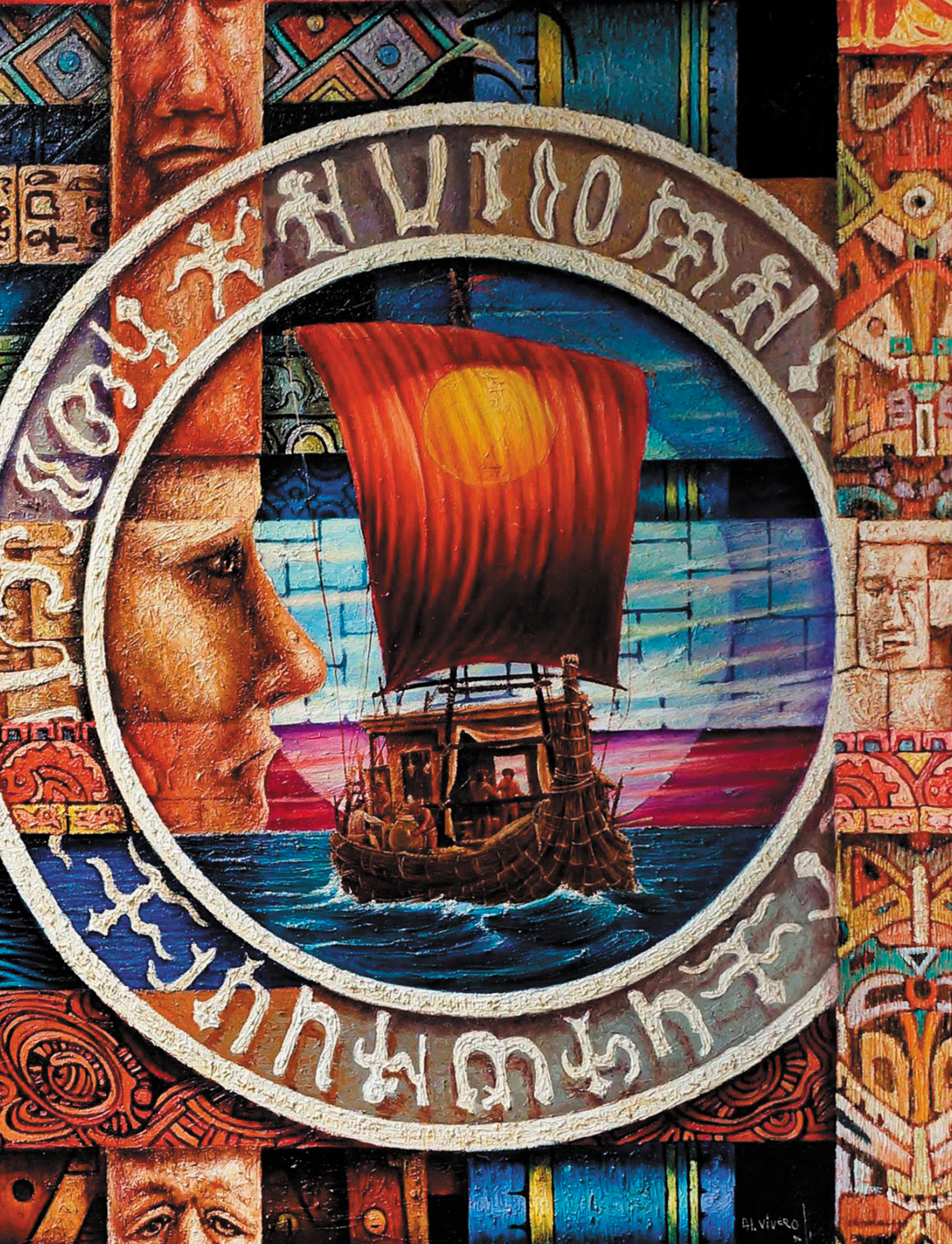




\title{
Poder, violencia y resistencia de la imagen. Batallas audiovisuales en América Latina*
}

* Este artículo es el resultado del trabajo desarrollado dentro del Grupo de Investigación Cultura Visual, Comunicación y Decolonialidad [CUVICODE].

\section{Artículo de reflexión}

\section{Miguel Alfonso Bouhaben}

Escuela Superior Politécnica del Litoral; Universidad de las Artes de Ecuador. miguel.alfonso@uartes.edu.ec

\begin{abstract}
(1)(2)
Cómo citar este artículo: Bouhanen, M. [2017]. Poder, violencia y resistencia de la imagen. Batallas audiovisuales en América latina, Calle14 revista de investigación en el campo del arte, 12(22), 214-225 DOl: https:/ /doi.org/10.14483/21450706.12354

\section{Resumen}

El mundo contemporáneo se ha convertido en imagen. El poder controla, por medio de imágenes -cámaras de vigilancia, películas ideológicas, nuevas tecnologías, etc.- lo que se debe pensar y sentir. El presente artículo tiene como objetivo la definición y la evaluación crítica de las relaciones entre el poder, la violencia y las formas de resistencia de las imágenes. A través del análisis de algunas secuencias de La hora de los hornos [Gettino y Solanas, 1968), Sangre de cóndor (Jorge Sanjinés, 1969] y El coraje del pueblo [Jorge Sanjinés, 1971], se valorarán las alternativas a los dispositivos de dominio audiovisual con el fin de poner contra las cuerdas la lógica de violencia visual del poder hegemónico. Se trata, en definitiva, de explorar las posibilidades de emergencia de las contraimágenes en el contexto de América Latina.
\end{abstract}

\section{Palabras claves}




\title{
Power, Violence and Resistance of the Image. Audiovisual Battles in Latin America
}

\begin{abstract}
The contemporary world has become an image. The power controls, through images - surveillance cameras, ideological films, new technologies, etc. - what should be thought and felt. This article aims at the definition and critical evaluation of the relations between power, violence and forms of resistance of images. Through the analysis of some sequences from The Hour of the Furnaces [Gettino and Solanas, 1968), Blood of the Condor [Jorge Sanjinés, 1969) and The Courage of the People [Jorge Sanjinés, 1971), the alternatives to the devices of audiovisual domain will be assessed in order to question the logic of visual violence of the hegemonic power. Finally, the purpose is to explore the possibilities of emergence of counter-images in the Latin American context.
\end{abstract}

\section{Keywords}

Latin America, Counter-image, power, resistance, violence.

\section{Puissance, violence et résistance de l'image. Batailles audiovisuelles en Amérique latine}

\section{Résumé}

Le monde contemporain est devenu une image. Le pouvoir contrôle, à travers des images -caméras de surveillance, films idéologiques, nouvelles technologies, etc. - ce qu'il faut penser et ressentir. Cet article vise la définition et l'évaluation critique des relations entre le pouvoir, la violence et les formes de résistance des images. Grâce à l'analyse de certaines séquences de L'Heure des brasiers [Gettino et Solanas, 1968), Sang du Condor [Jorge Sanjinés, 1969) et Le courage du peuple [Jorge Sanjinés, 1971), les alternatives à des dispositifs de domaine audiovisuel sont évaluées, afin de contester la logique de violence visuelle du pouvoir hégémonique. Enfin, il s'agit d'explorer les possibilités d'émergence de contre-images dans le contexte de l'Amérique latine.

\section{Mots clés}

Amérique latine, contre-image, pouvoir, résistance, violence.

\section{Poder, violência e resistência da imagem. Batalhas audiovisuais na américa latina}

\section{Resumo}

O mundo contemporâneo tem se transformado em imagem. O poder controla, por meio de imagens câmeras de vigilância, filmes ideológicos, novas tecnologias, etc - o que se deve pensar e sentir. 0 presente artigo tem como objetivo de resistência das avaliações crítica das relações entre o poder, a violência e as formas de resistência das imagens. Através da análise de algumas sequências La hora de los hornos [Gettino y Solanas, 1968], Sangre de cóndor [Jorge Sanjinés, 1969] e El coraje del pueblo [Jorge Sanjinés, 1971], se valorizarão as alternativas aos dispositivos de domínio audiovisual com o fim de pôr contra as cordas a lógica de violência visual do poder hegemônico. Definitivamente se trata de explorar as possibilidades de emergência das contra imagens no contexto da América Latina. 


\section{Palavras-chave}

América Latina, contra imagem, poder, resistência, violência.

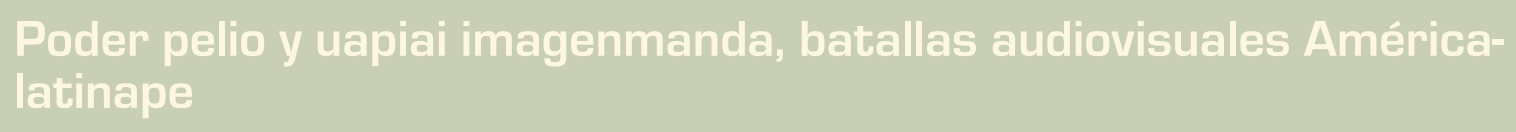

\section{Maillallachiska:}

Chi mundo contemporáneo convertirerka e imagen. Chi poderka controla chi imágenes- cámara de vigencia, películas ideológicas, musu tecnologías, etc.- deberenme iuiai y sentengapa. Kai presente articulok rukanme objetivo la definición y evaluacion crítica de las realciones entre poder, chi pilio y forma de resistencia de las imágenes. Atraves del análisis sug secuenciakuna la hora de los hornos [ Gettino y Solanas, 1968] iauar condorpa [ Jorge Sanjinés, 1969 ] y sug koraje pueblomanda [ Jorge Sanjinés 1971] se valoraran sug alternativakuna dispositivokuna de dominio audiovisual churrangapa contra las cuerdas sug lógica de pilio visual del poder hegemonico, tratarenme en definitiva, explorangapa sug posibilidadkuna de emergencia sug contraimagenkunamanda contextope América Latinape.

\section{Rimangapa Ministidukuna:}

América Latina, contraimagen, poder, uapiai, pilio.

\section{De la pantallización de la vida a las contra-imágenes del poder}

La fórmula de Nicholas Mirzoeff, "la vida moderna se desarrolla en la pantalla” [2003: 11], a pesar de esconder una certeza, se queda quizá en la superficie de las complejas y trabadas relaciones que se establecen entre la imagen y lo social. La vida no solo se desarrolla en la pantalla, sino que se ha convertido en pantalla. Actualmente, a lo que estamos asistiendo es a una pantallización de la vida, que hace de esta un simulacro y un espectáculo banal. Todo pantallizado: tanto lo que miramos [imágenes en internet, en la televisión, en la publicidad] como lo que nos mira [cámaras de videovigilancia); tanto a nivel macroscópico [Hubble y el deseo de saber que hay mas allá de nuestro mundo] como en el nivel microscopio [Roentgen y deseo de ver lo cada vez mas pequeño]; tanto en la horizontal [recordemos la importancia del horizonte en la construcción de la perspectiva artificialis] como en la vertical (la ubicuidad y el poder jerárquico de google maps]. Una experiencia que modifica nuestra relación con el mundo al entreabrir la posibilidad de visualizar lo no visual, lo que no se ve. Los sujetos y los objetos; lo grande y lo pequeño; el arriba y el abajo. Alli donde se trazan los límites de la experiencia llega la imagen y, bajo su dominio omnisciente, todo lo ve. Como Dios: de todo lo visible y lo invisible.

¿Es este el objetivo con el que nacieron la fotografía y el cine? ¿Es la función de estos instrumentos de captura de lo real el ejercicio de absoluto dominio sobre la realidad social? Sería injusto demonizar a estos dispositivos de captura y registro, ya que son solo medios. Los problemas de alienación y sometimiento soft que sufrimos en nuestros días se deben al uso que las grandes corporaciones económicas hacen de los mismos para hacer valer sus intereses. Pero, en su origen, el cine fue un instrumento para ejercer la libertad, para captar el movimiento de la vida, para crear más allá de los clichés dominantes. Es importante señalar como, en las primeras décadas del siglo $X X$, se acercaron al cine artistas, poetas y cineastas. Si vemos ahora los primeros filmes de las vanguardias históricas podemos corroborar como el cine es un instrumento que reivindica la vida, lo creativo, lo nuevo. Y, apuntémoslo, no es casualidad que justo en esa misma época emerjan las corrientes vitalistas en el seno de la filosofía. También a finales del siglo XIX y principios del $X X$, la vida fue objeto de vindicación por filósofos con Friedrich Nietzsche y Henri Bergson. Para Nietzsche, la vida no solo era el valor supremo que le servía para dinamitar el 
orden moral establecido por Platón, sino también el modo de definir la realidad como agitación imprevisible, caótica y en devenir; en un retorno a la reflexión heraclítea. Bergson, por su parte, entendía que la vida era el proceso de la diferencia, esto es, que era algo indeterminado y libre. La fotografía y el cine son dispositivos técnicos que permiten captar lo fugitivo del tiempo, plasmar los rumores y las incertidumbres de lo vital. Ahora bien, representar la vida, volver a repetirla, era algo que para muchos carecía de interés. Los propios hermanos Lumière sostenían que el cine era un invento sin futuro. Quizá por esta razón, los primeros que se acercan al cine son los artistas, los poetas y los magos que hacen de este instrumento su medio para crear. Y, siguiendo a Gilles Deleuze [que afirma que toda creación es delirio] también para delirar. Esto es, para hacer algo que puede resultar hermoso, enigmático y sorprendente, por supuesto, pero en todo punto inútil. Hasta que Edwin S. Porter descubre el montaje y con él, un nuevo modo para contar historias. Y, no hay que olvidarlo, los modos de contar historias han sido siempre de gran utilidad para aquellos que ejercen el poder. Las narraciones y los mitos son los que hacen sociedad. Por ello, cuando Hollywood descubre el potencial del cine, entonces se pone manos a la obra para contar los mitos que sirvan de soporte a los valores de la sociedad norteamericana con el fin de exportarlos a todo el mundo. Toda una globalización de los valores hegemónicos de Estados Unidos por medio de lo visual que conlleva un poderoso etnocentrismo: una globalización visual que progresivamente va convirtiendo la vida en una representación [teñida por los valores norteamericanos], es decir, en una pantalla. "USA por encima de todo", repite Jean-Luc Godard en Made in USA.

Ahora bien, ¿qué es lo que hace el poder con las imágenes? Como hemos apuntado, en el nuevo orden mundial postmoderno y postdemocrático, las imágenes son el vehículo para la transmisión de lo que se debe pensar y sentir: trazan el criterio de las posibilidades, o, por decirlo en el lenguaje de Kant, las condiciones de posibilidad del conocimiento y de la moral. Por ello, vamos a definir tres funciones que el poder pone en marcha a través de diferentes prácticas visuales con el fin de ejercer el control y la ideologización:

\section{El control y la videovigilancia. Las cámaras se} utilizan en muchas ocasiones para registrar lo que acontece en los centros comerciales, las autopistas y las calles. La videovigilancia es un modo de control omnisciente de la esfera pública: la sociedad siempre está controlada por las imágenes. Se trata de controlar por medio de la imagen, que no es otra cosa que luz. Es la imagen del panóptico: "El dispositivo panóptico dispone unas unidades espaciales que permiten ver sin cesar y reconocer al punto. En suma, se invierte el principio del calabozo; o más bien de sus tres funciones -encerrar, privar de luz y ocultar-; no se conserva más que la primera y se suprimen las otras dos. La plena luz y la mirada de un vigilante captan mejor que la sombra, que en último término protegía. La visibilidad es una trampa" [Foucault, 1990: 203]. En consecuencia, la sociedad se ha convertido en un panóptico donde las cámaras de vigilancia gobiernan y ejercen su violencia visual sobre los movimientos de los ciudadanos.

\section{La ideologización y el cine hegemónico. Las}

imágenes del cine de ficción sirven para transmitir los valores dominantes. Mediante los relatos audiovisuales se ejerce un control ideológico: la sociedad está siempre ideologizada por las imágenes. Sobre estas cuestiones han reflexionado Guy Debord, Louis Althusser o Jean Baudrillard. Debord afirma que la sociedad capitalista es la suma de sus espectáculos, lo cuales, convierten lo real, la vida, en una representación: "Toda la vida de las sociedades en que reinan las condiciones modernas de producción se anuncia como una inmensa acumulación de espectáculos. Todo lo que antes era vivido directamente se ha alejado en una representación" [2002: 8). Aparte de ser una recreación del famoso inicio del El Capital de Marx, en este aforismo podemos entrever una correlación con la crítica nietzscheana a los conceptos. Así, podemos decir que para Debord los espectáculos son esos conceptos que reducen, sepultan y enmascaran la vida. Ahora bien, esta sociedad del espectáculo está alineada, o mas bien, necesita, para ponerse en marcha, de lo que Althusser llama Aparatos Ideológicos. Entre otros muchos, los Aparatos Ideológicos de la información utilizan las imágenes para reproducir las condiciones de producción de la sociedad: "el aparato de información atiborrando a todos los "ciudadanos" mediante la prensa, la radio, la televisión, con dosis diarias de nacionalismo, chauvinismo, liberalismo, moralismo, etcétera." [1988: 34]. Recordemos que para el autor de "Ideología y aparatos ideológicos del estado" toda sociedad necesita reproducir sus condiciones de producción y, para ello, el cine es un arma irrenunciable. Por su parte, Baudrillard abunda en estas cuestiones al afirmar que la gran victoria del imperialismo consiste en hacer creer a los ciudadanos que sus simulacros, sus imágenes, sus espectáculos y sus aparatos ideológicos son lo real: "Lo único que quizá subsiste es el concepto de Imperio, pues los actuales simulacros, con el mismo imperialismo de aquellos cartógrafos, intentan hacer coincidir lo real, todo lo real, con sus modelos de simulación" [1978: 6]. Por tanto, la sociedad se ha convertido en un espectáculo, una simulación donde el cine hegemónico ejerce su violencia ideológica. 
3. El ciberfetichismo y las imágenes en red. Nuestra sociedad se ha convertido en una sociedad-imagen gracias a las posibilidades abiertas por las nuevas tecnologías y las redes sociales. Muchos consideran que internet va a posibilitar que las multitudes conectadas promuevan un movimiento ciudadano de emancipación contra el poder dominante. Yolanda Quintana y Mario Gascón en Ciberactivismo defienden que las relaciones en internet son ultrademocráticas: su estructura y dinámica son las de una "multiplicidad de actores que actúan en diferentes frentes simultáneamente y que se organizan sin plan previo y sin líder, de forma natural". Como internet, es un modelo en red distribuido en el que "todos somos potencialmente activistas" (2012: 28). Ahora bien, esta es la última revuelta de tuerca del poder: hacer creer que todo se puede cambiar desde internet, esto es, que las sociedades que allí se tejen son más reales que la propia realidad. El sociólogo César Rendueles ha definido esta ilusión como ciberfetichismo en el prólogo de su libro Sociofobia: "Tras el derrumbe de la utopía neoliberal, el gran consenso ideológico de nuestro tiempo es la capacidad de las tecnologías de la comunicación para inducir dinámicas sociales positivas [...] las redes sociales son el remedio a la fragilización de nuestras vidas nómadas y globalizadas; la ciberpolítica aspira a regenerar nuestras democracias exhaustas [...]. Sociofobia cuestiona, en primer lugar, este dogma ciberfetichista. La ideología de la red ha generado una realidad social disminuida, no aumentada" [2013: 5]. Con esto, la sociedad deviene sociedad sociofóbica cuando internet, con su maraña de imágenes fluctuantes, se presenta como el espacio utópico para el ejercicio de la libertad y la democracia.

Así, en esta guerra de los poderosos contra la humanidad, de ese $0,5 \%$ de la población contra el resto, las imágenes son de gran utilidad para controlar, ideologizar y fomentar el simulacro de la ciberpolítica y, por esta razón, las perspectivas de cambio social resultan sumamente difíciles. Casi heroicas. Ahora bien, no cabe duda que, en este esfuerzo, la ciudadanía ha de apropiarse de las armas de la imagen para contrarrestar estas imágenes del poder. $\mathrm{Si}$ analizando los dispositivos del poder observamos que el uso de la imagen ha sido decisivo en la configuración de esta sociedad de imágenes, sociedad pantallizada, sociedadpanóptico, sociedad-espectáculo, sociedad-ideologizada, una sociedad-simulacro, una sociedad-sociofóbica; entonces es preciso contrabalancear estas imágenes con otras resistentes y críticas. Esto es, hacer el contraplano de esas imágenes.

Paul Virilio da en la clave cuando afirma que en las guerras actuales los mapas han sido sustituidos por las imágenes. Ya no se trata de trazar un mapa para ver al enemigo. En una entrevista publicada en España bajo el título El Cibermundo. Políticas de lo peor sostiene:

Todo conflicto es un campo de percepción [...] Hasta la primera guerra mundial, la guerra siempre se había hecho con mapas [...] Los primeros aviones no servirán para combatir sino para observar desde lo alto, al igual que los primeros globos sirvieron para fotografiar las líneas enemigas. Así pues, el cine, el fotomosaico y el documental servirán para hacer la guerra y para favorecer una visión ampliada del campo de batalla. En el pasado, para atisbar al enemigo, se subía a un punto alto o a una atalaya y se le veía venir. En la época que nos ocupa se utiliza el avión y la cámara para tratar de localizar al adversario (...) A partir de ese año, la guerra se convierte en una película de guerra; ya no se trata de los cuadros de batallas o mapas marcados en rojo o azul, sino de una película [2005: 29].

¿Puede hacer algo el ciudadano con las imágenes? ¿Cómo denunciar la violencia, la opresión y la injusticia perpetradas por el poder? ¿Qué tipo de películas hay que crear para enfrentarse al enemigo? Lo importante es asumir que es imprescindible crea una contra-imagen del poder. Si, como señala Eduardo Galeano, "no hay escuela que no encuentre su contraescuela" [1998: 10), entonces no hay imagen del poder que no encuentre su contra-imagen.

\section{La violencia de las imágenes hegemónicas en América Latina}

En el contexto latinoamericano estas formas de control, ideologización y fetichismo por medio de la imagen han sido claves en los diferentes procesos de colonización y de globalización capitalista en América Latina. Hagamos un breve balance del modus operandi de la colonización y la globalización capitalista con el fin de, posteriormente, valorar los dispositivos estéticos que ponen en marcha.

En primer lugar, hay que señalar que los procesos de colonización son inseparables de los desarrollos de la modernidad. ¿Por qué razón los teóricos de la decolonialidad hablan del sistema modernidad/colonialidad? El motivo no es otro que el de su absoluta copertenencia, en la medida en que el desarrollo de la modernidad solo fue posible gracias a la violencia colonial. Si las ideas platónicas de Justicia, Verdad y Belleza estaban dispuestas a ser descubiertas por los hombres [y no las mujeres] libres [y no esclavos] adultos [y no ancianos o niños] destinados a gobernaren la polis; de igual modo, las ideas ilustradas de Libertad, Igualdad y Fraternidad se circunscribían exclusivamente al ámbito europeo de manera que los otros [los negros o los indios] ni 
eran libres, ni iguales a los europeos y, sin duda, tampoco se podía establecer con ellos ningún tipo de relación fraternal. Esta exclusión de los otros, de los subalternos, ha sido una constante en toda la tradición europea de Grecia a la llustración que, a la vez que se lanzaba a la búsqueda sin tregua de lo universal, cimentaba la infravaloración de los saberes de los pueblos conquistados. Immanuel Wallerstein [2001] apunta que la fuerza de la historia, de la civilización y del progreso son los elementos epistémicos que Occidente ha puesto como superiores a cualquier otro saber. Ahora bien, la ciencia europea, en el devenir de la colonización, no solo atenta y margina los otros saberes, sino que también hace uso de categorizaciones y taxonomías raciales, que establecen jerarquizaciones que sitúan en la cúspide al blanco-europeo y que expulsan casi a la condición de animal irracional a los indios y los negros. El sacrosanto Kant escribe: "La humanidad encuentra su mayor perfección en la raza de los blancos. Los indios amarillos tienen un talento menor. Los negros están muy por debajo, y en el lugar inferior está una parte de los pueblos americanos" [Citado por Hecerg, 2010: 410]. Está claro que para Kant el color de la razón pura es blanco puro. Sin embargo, las otras razones resultan algo más oscuras. Ciertamente, estas consideraciones racistas parecen no encajar en la ley moral enunciada por Kant en el Imperativo Categórico: obra de tal modo que la máxima de tu acción sea ley universal.

Pero, ¿cómo es posible imponer esta violencia epistémica y ética? La respuesta, en principio, es simple: mediante la violencia de la teoría y la praxis artística, es decir, a través de la construcción de un sistema teórico que determine la ley de lo bello: "El discurso filosófico impuso un canon de principios para definir el quehacer artístico y para definir también una zona en la cual lo artístico se diferencia de lo no artístico (artesanado, pintura y poesía popular, mitos y leyendas y no literatura, canciones populares y no música propiamente dicha, etc.]" [Gómez y Mignolo, 2012: 14). Así, por mediación de la praxis, las formas artísticas colonizan todo lo sensible, toda la vida social: "la colonialidad de lo sensible, se despliega en especial a través de los regímenes del arte y la estética que hacen parte de la expansión de la matriz colonial de la modernidad, en un abanico de formas mediante las cuales se pretende, más allá del exclusivo espacio del arte, abarcar la totalidad de los ámbitos de la vida" [15].

De este modo, el sistema modernidad/colonialidad que se despliega del siglo XV al XVIII utiliza la violencia estética para crear valores etnocéntricos y racistas. Con todo, a partir del XVIII, de la mano de la modernidad, aparece un nuevo modelo económico basado en la plusvalía: el capitalismo. Este sistema profundiza en los modos de control y opresión de la colonización y, ciertamente, supone una suerte de protocapitalismo. El filósofo posestructuralista Gilles Deleuze, que ha influido en muchos de los pensadores que han estudiado las problemáticas indígenas, describe a la sociedad como un flujo de cosas que circulan y que son codificadas y resignificadas para ser comprendidas. El capitalismo es una máquina axiómatica que permite recodificar aquellos flujos no controlables: siempre establece una idea por encima de aquello que no entiende con el fin de hacerlo comprensible: "el capitalismo dispone de una especie de axiomática, dispone entonces de algo nuevo que no se conocía. Y esta es, como sucede con todas las axiomáticas, una axiomática, al límite, no saturable; lista para añadir siempre un axioma de más que hace que todo vuelva a funcionar" [1971: 4]. Pero, ¿qué pasa cuando hay en el seno de una sociedad cosas que no se pueden controlar? Para Deleuze, el capitalismo tiene dos modos de control: la eliminación física o la recodificación semiótica. Son los dos tipos de violencia para establecer su orden dominante: "Una sociedad puede codificar la pobreza, la penuria, el hambre; lo que no puede codificar, es cuando aparece esa cosa, entonces se dice: i¿qué es esa gente?! Entonces, en un primer momento, se agita el aparato represivo, si no se los puede codificar, se intenta aniquilarlos. En un segundo momento, se intenta encontrar nuevos axiomas que permitan, bien que mal, recodificarlos" [1971: 4). En lo que sigue, vamos a juzgar los modos de violencia física y semiótica que Estados Unidos ha impuesto a los pueblos latinoamericanos.

Respecto a la violencia física que Estados Unidos ha desplegado en América Latina, podemos consultar la obra de Noam Chomsky (1993) y de Eduardo Galeano [1986]. Estos usos de la violencia física no han sido otra cosa que el medio para imponer y perpetuar el avance del capitalismo globalizado por medio de golpes de estado, asesinatos, invasiones y derrocamientos. Las invasiones de EE.UU. en América Latina son casi incontables. Cada vez que ha habido un intento de conformar un gobierno democrático, EE.UU. se ha encargado de imposibilitarlo. De ahí la incompatibilidad esencial entre capitalismo y democracia. Ahora bien, esta violencia física va de la mano de una violencia semiótica, que es el modo de control que se ejerce mediante la resignificación, que no es otra cosa que un totalitarismo simbólico que recodifica toda contracción cultural. Pero no siempre es posible esta totalización. Algunas comunidades indígenas son impermeables a dichos procesos. Viveiros de Castro observa, siguiendo la senda de Deleuze, cómo las comunidades indígenas son sociedades ajenas a estos procesos de totalización: "[Deleuze] veía una ontología política distinta, en esa forma de vida esencialmente menor, ese carácter minoritario de la vida indígena, la cantidad de mecanismos que traban o bloquean el surgimiento de un 
discurso mayor en esas sociedades, desde la ausencia de ortodoxia, la ausencia de doctrina, la ausencia del Estado. Esa idea de sociedad como multiplicidad me parecía muy evidente en el mundo indígena. Esa incapacidad de totalizar. Lo que suelen denominar como "primitivo", es justamente esa imposibilidad que ella se ofrece así misma de transformarse en totalidad" [Viveiros de Castro, 2009: 266). En este esfuerzo por aplanar y vaciar toda cultura ajena a la hegemónica, los medios de comunicación visual ejercen un papel decisivo. Ariel Dorfman y Armand Mattelart en Para leer al Pato Donald, título inequívocamente althusseriano, dan cuenta de las formas que el colonialismo y el capitalismo globalizado, representado en la cultura de masas estadounidense, usan para infravalorar a las subjetividades subalternas. "Detrás del azucarado Disney, el látigo" [1972: 26], escriben Dorfman y Mattelart. Esta consigna puede servir para dar cuenta de los procesos de resignificación que el poder del capital pone en práctica: el azúcar de la máquina semiótica y el látigo de la máquina de guerra.

\section{La representación de la violencia en el cine resistente de los años 60}

Una vez que hemos dado cuenta del poder de la imagen y de sus usos para el control y la ideologización, resultan imprescindibles, en la batalla por el sentido y por la razón, forjar contra-imágenes. Sí, estamos en guerra y, como señala Virilio, las guerras actuales se hacen con imágenes. Los medios de comunicación de masas de los países desarrollados han construido sus imágenes: imágenes que ejercen su violencia para dar continuidad a las estructuras de los sistemas de la modernidad/colonialidad y del capitalismo globalizado. A continuación, vamos a analizar y a evaluar de qué modo el cine resistente de los años 60 en América Latina ha creado contra-imágenes de dicha violencia visual. Para ello, analizaremos algunas secuencias de La hora de los hornos [Gettino y Solanas, 1968), de Sangre de cóndor [Jorge Sanjinés, 1969] y de El coraje del pueblo [Jorge Sanjinés, 1971], con el fin de poner contra las cuerdas a la lógica de la violencia visual

\section{Octavio Gettino y Fernando "Pino" Solanas. Crítica de la violencia estructural contra el subdesarrollo}

En la primera parte de La hora de los hornos, film argentino realizado por Octavio Gettino y Fernando "Pino" Solanas en 1968, ambos miembros fundadores del Grupo Cine Liberación, encontramos una secuencia que supone la espina dorsal de su proyecto. En la primera imagen de dicha secuencia [Figura 1], la cámara se desplaza lentamente hacia la derecha y registra una gran ciudad: una maraña de rascacielos que simbolizan el poder económico y el progreso social y cultural. Sobre esta imagen, se instala una voz en off, que contrabalancea y hace entrar en crisis a lo visible, pues explica cómo lo que vemos, la bonanza y prosperidad de los llamados países desarrollados, solo es posible a través de la opresión de las gentes de los llamados países subdesarrollados, que son convertidos en mano de obra barata. El relato de la voz en off termina con la siguiente afirmación: "eso dio lugar a una oscura palabra inventada por el imperialismo". Justo en ese momento, hay un cambio de plano: en la banda de imagen se abre la compuerta de un matadero [Figura 2], como una suerte de subida de telón que da inicio al espectáculo de la violencia estructural, a la vez que la voz en off formula la palabra "Subdesarrollo". Tras abrirse la compuerta, caen los cuerpos sin vida de varios terneros y la voz desaparece y es sustituida por una triste canción tarareada por una voz femenina, que balbucea sinsentido, subrayando la quiebra de sentido de este sistema de vasos comunicantes que manda al matadero a los otros, a los subalternos, para que en Occidente las gentes consuman y sonrían. En las subsiguientes imágenes, los terneros son desplazados por ganchos, boca abajo, vomitando sangre [Figura 3] y, a partir de ahí, comienza la relación macabra, la dialéctica bellaca entre la muerte y el consumo: imágenes del desarrollo se intercalan, carteles de neón, publicidad, felicidad [Figura 4]

[Figura 1]

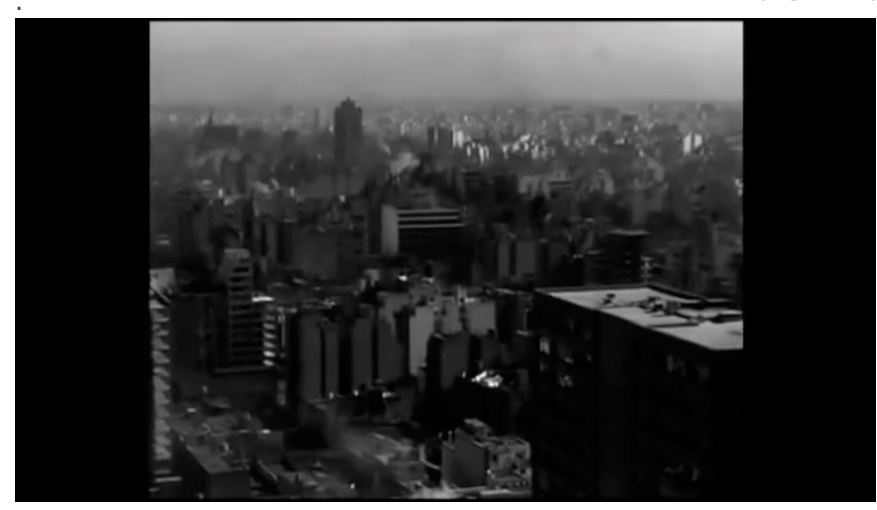

[Figura 2]

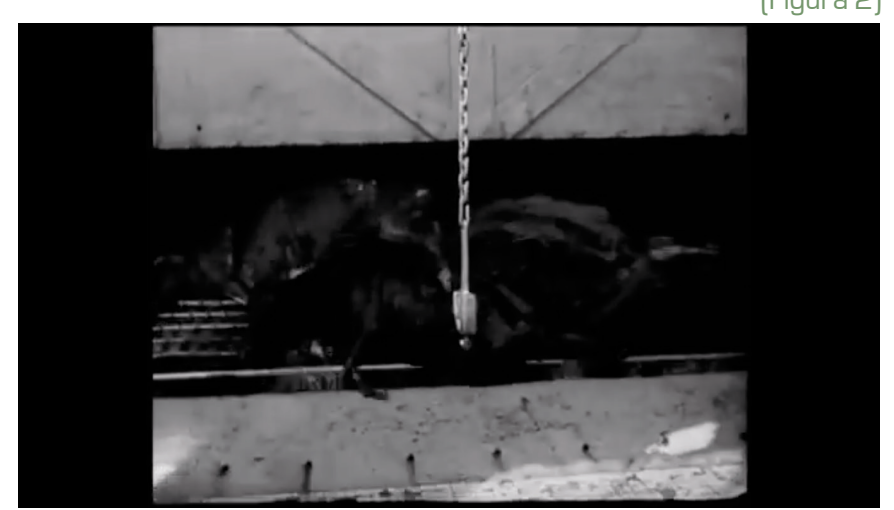




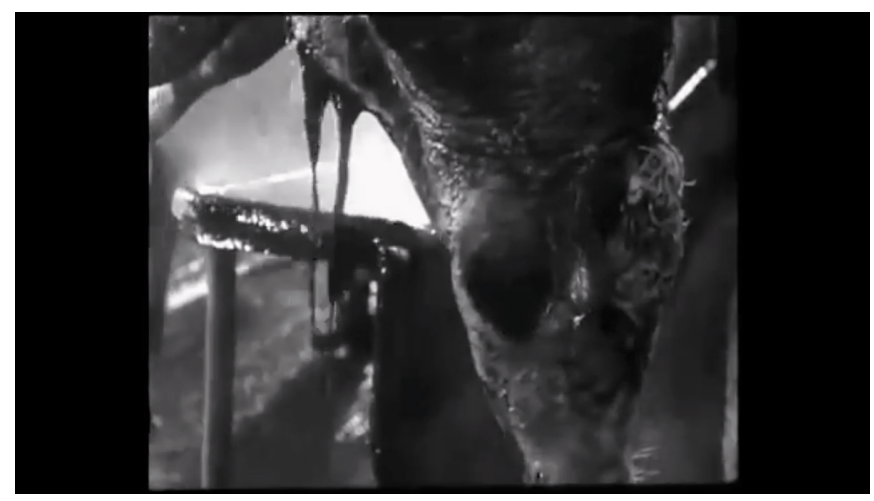

[Figura 4]

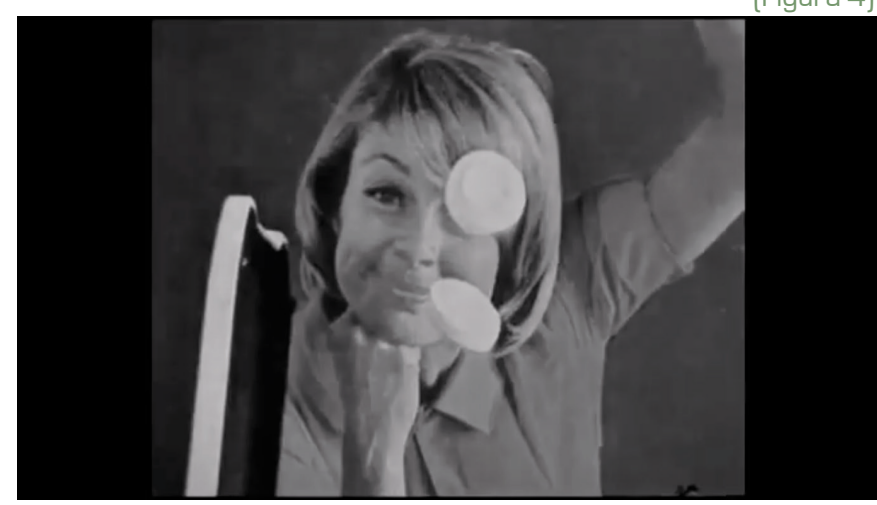

Figuras 1-4. La hora de los hornos [Octavio Gettino y Fernando "Pino" Solanas, 1968]

Sin duda, este proceso de contraposición, de montaje alterno entre las imágenes del matadero y las del consumo, ejemplifica la violencia estructural denunciada por las tres corrientes de pensamiento que en esos mismos años iniciaban su andadura crítica en América Latina. Nos referimos a la Teoría de la Dependencia y la Teología de la Liberación. La Teoría de la Dependencia centra su crítica en la teoría económica neoliberal, que defiende que las diferencias entre los países desarrollados y subdesarrollados depende de factores evolutivos $y$, por ende, sostiene que el progreso es una línea de estadios sucesivos. Por el contrario, la Teoría de la Dependencia desaprueba esta tesis y muestra cómo las diferencias entre países desarrollados y subdesarrollados se deben a una situación estructural propiciada por un orden injusto y desigual del sistema político-económico del capitalismo, que beneficia a los países poderosos del Primer Mundo y lanza al abismo a los países periféricos. Andre Gunder Frank, uno de los más relevantes teóricos de la Dependencia afirma: "El subdesarrollo no es consecuencia de la supervivencia de instituciones arcaicas, de la falta de capitales en las regiones que se han mantenido alejadas del torrente de la historia del mundo, por el contrario, el subdesarrollo ha sido y es aun generado por el mismo proceso histórico que genera también el desarrollo económico del propio capitalismo" (Frank, 1967: 33).

La Teología de la Liberación va a denunciar esa violencia estructural. Ella introduce la idea de que la salvación cristiana no puede ser posible sin la liberación políticoeconómica. Uno de sus prepuestos fundamentales consiste en considerar que la situación de desigualdad de los países latinoamericanos es un pecado social, un pecado estructural cometido por los poderes económicos. Gustavo Gutiérrez, uno de los máximos exponentes de la Teología de la Liberación apunta que "como se ha observado con insistencia en los últimos años, el prójimo no es solo el hombre tomado individualmente. Es, más bien, el hombre considerado en la urdimbre de las relaciones sociales. Es el hombre ubicado en sus coordenadas económicas, sociales, culturales, raciales. Es, igualmente, la clase social explotada, el pueblo dominado, la raza marginada. Las masas son también nuestro prójimo" [Gutiérrez, 1972: 33]. Y, al igual que los teóricos de la Dependencia, aboga por la liberación de los oprimidos.

Dichas propuestas teóricas van a tener un influjo decisivo en "Hacia el tercer cine", el texto-manifiesto que escriben Gettino y Solanas y que conforma una suerte de díptico con La hora de los hornos. Fundamentalmente, el texto pretende trazar los elementos esenciales para construir un cine de liberación decolonial. En primer lugar, los autores hacen hincapié en la importancia del cine como medio de penetración cultural y de colonización pedagógica. El problema es que siempre ha estado en manos del poder económico, sobre todo, estadounidense: "[El cine es] el instrumento de comunicación más valioso de nuestro tiempo estaba destinado a satisfacer exclusivamente los intereses de los poseedores del cine, es decir, de los dueños del mercado mundial del cine, en su inmensa mayoría estadounidenses" (Citado en Velleggia, 2009: 337). Por ello, para contrarrestar los efectos ideológicos del cine hegemónico hay que inventar otro cine. El tercer cine: un cine de la subversión y de la destrucción de los valores dominantes del capitalismo y el neocolonialismo. Este tercer cine se hace eco de las luchas antiimperialistas de los pueblos del tercer mundo, de los llamados subdesarrollados, para promover la decolonización de la cultura: del cine industrial, del cine de autor, del cine comercial, del cine espectáculo: "El hombre del tercer cine [...] opone ante todo, al cine industrial, un cine artesanal: al cine de individuos, un cine de masas; al cine de autor, un cine de grupos operativos; al cine de desinformación neocolonial, un cine de información; a un cine de evasión, un cine que rescate la verdad; a un cine pasivo, un cine de agresión; a un cine institucionalizado, un cine de guerrillas; a un cine espectáculo, un cine de acto, un cine acción; a un cine de destrucción, un cine simultáneamente de destrucción y de construcción; a un cine hecho para el hombre viejo, para ellos, un cine a la medida del hombre nuevo: la posibilidad que somos cada 
uno de nosotros" [Citado en Velleggia, 2009: 367].

\section{Jorge Sanjinés: Violencia y resistencia}

El director boliviano Jorge Sanjinés ha reflexionado en sus películas sobre el uso de la violencia. Su posición teórica supone un paso hacia la acción: ya no se trata de adoptar una posición defensiva que se ciña a la identificación de los problemas, de los efectos, sino apuntar a las causas con el fin de dar una respuesta violenta y revolucionaria a la miseria impuesta por el imperialismo, en consonancia a los presupuestos defendidos por Franz Fanon en Los condenados de la tierra. En Testimonios de Mérida [1969), el director boliviano afirma: "Creo que ahora debemos entrar a una etapa mucho más agresiva, ya no defensiva, sino ofensiva, debemos desenmascarar a los culpables de las tragedias y de la tragedia latinoamericana. Debemos señalar quiénes son los que causan este estado de cosas. Debemos desenmascarar al imperialismo, eso debemos hacer [...] propuse pasar de la etapa defensiva -consistente sólo en denunciar el estado de miseria de nuestros pueblos-, a una etapa más agresiva, a una etapa ofensiva, es decir, a denunciar a los causantes de ese estado de miseria, a señalar a los culpables y a explicar las estructuras de la explotación hasta llegar a acusar, individualizando, al imperialismo y a sus cipayos. Yawar Mallku es el fruto de esa posición" [Sanjinés, 1969: 98]. Esa posición ofensiva abre una puerta a la justificación de la violencia revolucionaria. En un mundo a la deriva, cuando los derechos más básicos no son respetados, cuando la ética está erosionada, las respuestas violentas de los oprimidos son un argumento cada vez más probable: "la ética no encuentra referencias aceptables y la violencia surge como la posibilidad más aceptable" [en Aimarreti, 2012: 13). Ahora bien, se trata de usar la violencia para, mediante la fuerza, conquistar un lugar de enunciación, un lugar para poder hablar y reivindicar lo que es justo. Si se niega a la gente la palabra, esto es, la negación del poder decir propia de los subalternos, entonces la violencia puede tener un carácter moral, en el sentido en que reclama hablar, que es como dijo Aristóteles aquello que nos hace no solo personas, sino también ciudadanos.

En Sangre de Cóndor [Jorge Sanjinés, 1969] se dibuja una tensión fuerte entre la violencia colonial y la violencia decolonial. El colonialismo -igual que el capitalismo globalizado- utiliza medios múltiples para infravalorar el colonizado. En este film, el cineasta boliviano se basa en hechos reales para mostrar un conflicto entre el mundo occidental y el mundo colonizado. En su obertura, Sanjinés sitúa la cita de un científico que afirma que hay que eliminar a la raza de los inferiores, basándose en su carácter esencialmente animal. Así comienza el proceso de deshumanización de los indígenas: son lo otro irracional que hay que eliminar. Para ello, viajan a Bolivia en misión "humanitaria" los llamados Cuerpos de Paz estadounidenses, cuya finalidad no confesada es la esterilización de las mujeres indígenas. Al ser descubiertos, los indígenas se rebelan contra ellos y los castran, en una suerte de ojo por ojo. Los rebeldes son fusilados y el protagonista de la película no puede salvar a su hermano herido, porque no tiene dinero para pagar al hospital. Toda esta maraña de opresión a llevar al pueblo a tomar las armas. La última escena de la película muestra unos fusiles alzados, dispuestos a combatir a los colonizadores [Figura 5]. Suena paradójico, pero cuando no tienes palabra la violencia parece el único modo de reclamarla.

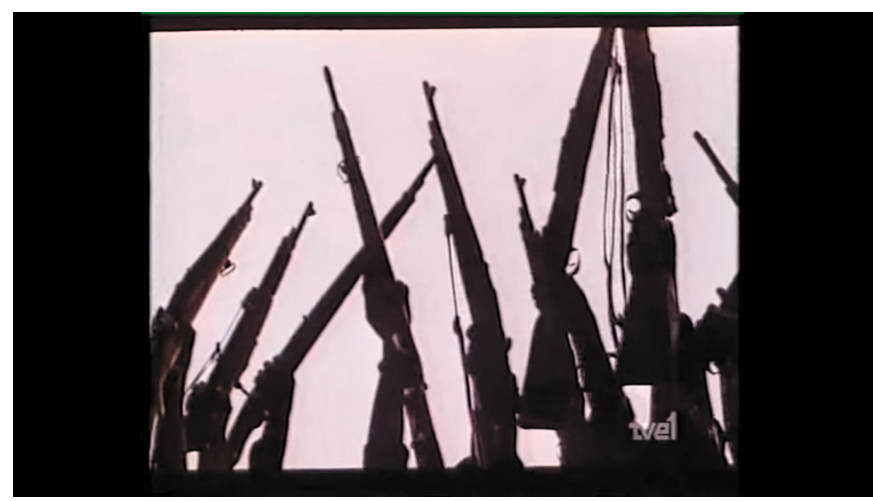

Figura 5. Sangre de Cóndor [Jorge Sanjinés, 1969]

Los actos de esterilización son una negación al derecho a tener descendencia, al derecho a vivir. Todo un proceso de aniquilación que desemboca en revolución: "En el discurso planteado en esta película, existe un choque entre la cultura occidental y las tradiciones del grupo de campesinos indígenas. Las esterilizaciones que los médicos 'gringos' ejercían sobre las mujeres se enfrentan a la importancia de la fertilidad en la comunidad aborigen. Además de ser considerada como una maldición, la imposibilidad de la concepción habla de un intento de aniquilación de la cultura. Más que una ayuda beneficiaria, este desempeño de los médicos extranjeros consiste en una lucha de poder. Es por eso que al final del film observamos la tesis final de Sanjinés: las manos del pueblo levantando armas para ejecutar justicia será una imagen recurrente en el cine latinoamericano de los años sesenta" [Flores, 2008: 21]. Respecto a esa última imagen, Sanjinés entiende que es la única conclusión posible a la opresión "Yo creo que, si estamos comunicándonos con la gente de alguna manera, es importante decirles que ellos tienen la capacidad de liberarse. Para mí, esto implica, sencillamente, una llamada a la violencia, una violencia que la gente no ha provocado, pero a la que hasta ahora han sido sometidos. La última toma estática de los brazos levantados en armas significa claramente, y sin duda, que la única solución para que los 
indios mejoren su situación y para que Latinoamérica se libere es la revolución" [1979a: 151].

En el Coraje de un pueblo [Jorge Sanjinés, 1971] encontramos un final que también sirve para interpelar al pueblo y convocarlo a la revolución. Este film fue un encargo de la Radiotelevisión Italina [RAl] sobre la vida minera que aprovecha Sanjinés para narrar la Masacre de San Juan, que se produjo el 24 de julio de 1967 en un poblado minero. Es el primer film donde trabaja de "adentro a fuera”, esquivando así toda producción paternalista al dar la palabra y la imagen a los protagonistas. "Al eliminarse la verticalidad del cine concebido a priori, se daba paso y se abrían las puertas a una participación real del pueblo en una obra que atañía a su historia y su destino. Se recordaron los diálogos de situaciones reconstruidas, se discutieron allí mismo, en los lugares del hecho histórico, con los auténticos protagonistas. Muchas veces los miembros del equipo asistieron pasmados a procesos de representación indetenibles. La cámara tenía por lo tanto que jugar un papel protagonista a su vez, debía situarse en los puntos de vista de los participantes y participar como un testigo más" [Sanjinés, 1979b: 23]. Esa cámaratestigo de los acontecimientos tiene como finalidad es esclarecimiento de aquellos hechos por medio de la participación activa los protagonistas, del pueblo.

Al igual que en Sangre de cóndor, la última escena del film atesora fuertes elementos resistentes y contestatarios. En la imagen [Figura 6], observamos como el pueblo camina unido. La cámara está en el interior, como un actor más. Además, el cineasta superpone un texto sobre la imagen, una consigna revolucionaria: "El pueblo luchará hasta la victoria"

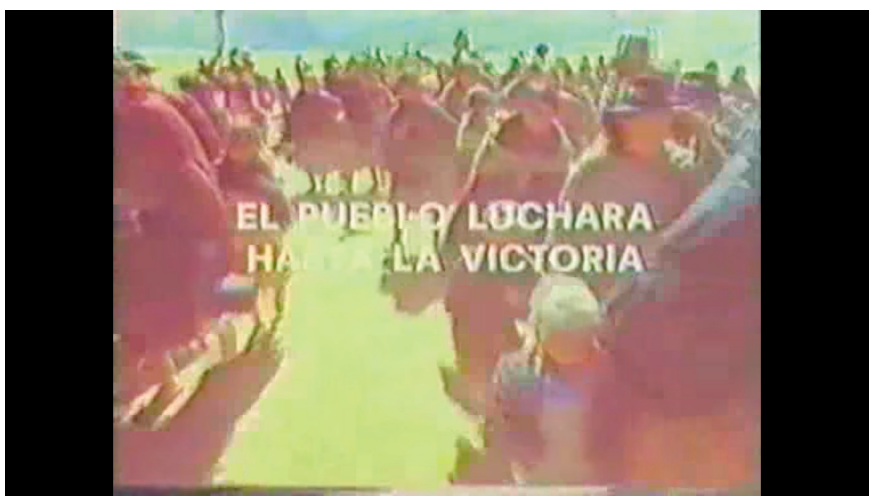

Figura 6. Coraje de un pueblo [Jorge Sanjinés, 1971]

Esta imagen da cuenta del carácter político de film. Si bien es cierto que el fin último es la liberación, esta, dado que no hay lugar para la palabra indígena, solo podrá lograse por medios violentos. "Todo el trabajo del grupo Ukamau es un trabajo de compromiso político: hacemos cine que va a construir o va a contribuir a construir un proceso de liberación, sea con una película que denuncie un hecho que se intenta ocultar como la masacre de San Juan -que se reconstruye en el Coraje del pueblo" [Sanjinés, 2008: 10].

\section{Conclusiones}

En esta guerra de imágenes, la pantallización de la vida, el dominio de la ideología dominante a través de lo visual, está venciendo a las contra-imágenes de los movimientos sociales. Ahora bien, hay que seguir en el esfuerzo por transformar este orden de injusticia y desigualdad. Y, para ello, resulta imprescindible continuar con la lucha con la imagen, desde la imagen.

Albert Camus escribió que para hacer filosofía había que escribir novelas, esto es, si queremos pensar, entonces tenemos que abandonar la abstracción conceptual para agarrarse a la carne de lo concreto que ofrece la literatura. Poco años después, Alexander Astruc defendió en un texto que lleva por título "La cámara-estilo", que los grandes pensadores del pasado, para construir sus sistemas de pensamiento, habrían hecho uso de las cualidades y las potencias que ofrece el cinematógrafo. Imaginemos a Descartes filmando el Discurso del método con una videocámara casera, o a Marx realizando una gran serie documental para contar El Capital. En el tiempo que nos ha tocado vivir, tiempo de un fuerte totalitarismo visual, es imprescindible utilizar las herramientas visuales. Los filósofos, sociólogos o politólogos actuales deberían de plantearse la posibilidad de dejar de escribir o, para ser más precisos, de empezar a escribir con imágenes y sonidos. Filmar los nuevos discursos, los nuevos mitos, las nuevas resistencias.

Recordemos que la hegemonía solo puede ser conquistada con mitos, en la medida en que estos son decodificados con mayor facilidad por el pueblo. 


\section{Referencias}

Aimaretti, M. G. [2012]. Revivir la experiencia, narrar la masacre, impugnar la Historia: sobre el uso del testimonio en El coraje del pueblo [Grupo Ukamau-Jorge Sanjinés, 1971). Afuera. Estudios de Crítica Cultural.

PMCid:PMC3314362

Althusser, L. [1988]. Ideología y aparatos ideológicos de Estado: Freud y Lacan. Buenos Aires: Nueva visión.

Baudrillard, J. [1978]. Cultura y simulacro. Barcelona: Kairós.

Chomsky, N. [1993]. Year 501: The Conquest Continues. Boston: South End Press.

Debord, G. [2002]. La sociedad del espectáculo. Valencia: Pretextos

Deleuze, G. [1971]. "AntiOedipe et Mille plateaux". Cours à Vincennes - 16/11/1971.

Dorfman, A., \& Mattelart, A. [1972). Para leer al pato Donald. Buenos Aires: Siglo XXI.

Flores, S. [2008]. "La obra cinematográfica como representación colectiva de las memorias populares: el caso de Latinoamérica en los a-os sesenta". En Perspectivas de la comunicación, Vol. 1, № 1.

Foucault, M. (1990]. Vigilar y castigar: nacimiento de la prisión. Barcelona: Siglo XXI

PMCid:PMC171908

Frank, A. G. [1967]. Capitalismo y subdesarrollo en América Latina. New York: New York University Press,

Galeano, E. [1998). Patas arriba: la escuela del mundo al revés. Buenos Aires: Siglo XXI.

\section{PMCid:PMC3988111}

Galeano, E.(2011). Memorias Del Fuego [II]: Las Caras Y Las Máscaras. Barcelona: Siglo XXI.

Gutiérrez, G. [1975]. Teología de la liberación: perspectivas. Salamanca: Sígueme.

Herceg, José Santos [2010]. Inmanuel Kant: del racialismo al racismo. Thémata. Revista de Filosofía, 43.
Mignolo, Walter; Gómez, Pedro Pablo [2012].

Estéticas decoloniales. Bogotá: Conf. Universidad Distrital Francisco José de Caldas.

Mirzoeff, N. [2003]. Una Introducción a la cultura visual. Barcelona: Paidós.

https://doi.org/10.1177/14704129030022009

Paranaguá, P. A. [2003]. Cine documental en América latina. Madrid: Cátedra.

Rendueles, C. [2013]. Sociofobia: el cambio político en la era de la utopía digital. Madrid: Capitán Swing.

Sanjinés, J. [1969]. Testimonio en Mérida [Venezuela]. Hojas de cine: testimonios y documentales del nuevo Cine Latinoamericano Vol, 1, 97-101.

Sanjinés, J.[1979a]: Ukamau y Yawar Mallku. Entrevista a Jorge Sanjinés. Revista Afterimage № 3 Verano 1971. Londres, reproducida en Carlos Mesa [coord.): Cine Boliviano: del realizador al crítico. La Paz: Editorial Gisbert.

Sanjinés, J.[1979b]. Teoría y práctica de un cine junto al pueblo. México: Siglo XXI editores.

Sanjinés, J. [2008]. El coraje de Sanjinés: un cine junto al pueblo. En http:/ / www.grupokane.com.ar/index. php?option=com_content\&view=article\&id=147:artentrevjo rgesanjines

Tascón, T. \& Quintana, Y. [2012]. Ciberactivismo. Las nuevas revoluciones de las multitudes conectadas. Madrid: Catarata.

Velleggia, S. [2009]. La máquina de la mirada: los movimientos cinematográficos de ruptura y el cine político latinoamericano. Quito: Editorial Altamira.

Virilio, P. [2005]. Cibermundo, la política de lo peor. Madrid: Cátedra.

Viveiros de Castro, E. [2013]. La mirada del jaguar. Introducción al perspectivismo amerindio. Buenos Aires: Tinta y limón.

Wallerstein, Inmanuel [2001]. "El Eurocentrismo y sus Avatares: los Dilemas de las Ciencias Sociales". Revista de Sociología, 15, pp. 27-39.

https:/ / doi.org/10.5354/0719-529X.2001.27767 